\title{
Thyroid screening in neonates: Indian perspective
}

\author{
Rabindran ${ }^{1}$, Gedam DS ${ }^{2}$ \\ ${ }^{1}$ Dr. Rabindran, Consultant Neonatologist, Billroth Hospital, Chennai, Dr D Sharad Gedam, Professor of Pediatrics, L \\ N Medical College, Bhopal, MP, India. Both are member of Editorial board of IJPR.
}

Address for correspondence: Dr Rabindran, E mail: rabindranindia@ yahoo.co.in

\begin{abstract}
Hypothyroidism is most common preventable cause of Mental retardation. Most of developed countries have been adopted neonatal thyroid screening programme three decades back. In India still congenital hypothyroism is important preventable cause of mental retardation. Universal Neonatal thyroid screening looks a distant dream in Indian scenario.
\end{abstract}

Key words: Hypothyroidism, Mental retardation, Thyroid screening

Neonatal Thyroid Screening began in 1974 by using heel prick filter paper blood sample, a technique pioneered by Guthrie in 1963 \&is now mandatory in most developed countries[1]. Around $25 \%$ of the 130 million babies undergo thyroid screening wordwide [2]. The incidence of primary hypothyroidism varies from 1 in 1000 to 1 in 3500 live births depending on iodine sufficiency, laboratory methods, screening practice, demographic, geographic \& racial/ethnic factors. In India about 10,000 babies are born with congenital hypothyroidism every year[3]. Four percent of Indian population are mentally retarded and $5-15 \%$ of sick newborns are thought to have a metabolic problem [4]. A recent ICMR Study revealed that Congenital Hypothyroidism affects 1 in 1172 newborn babies in India which is highly alarming when compared to worldwide statistics of 1 in 3,800 newborn babies [5] Only 50 per cent of all households are currently using adequately iodized salt\&out of 342 districts surveyed, 286 have been identified as endemic to iodine deficiency [6]. Research studies conducted in school age children, Adolescent girls, Pregnant Mothers and Neonates have documented poor iodine nutritional status. Thus mass screening will be useful to prevent disability and death by early intervention, follow-up and counselling.

The cost benefit ratio of Thyroid screening is 10:1. Majority use filter paper $\mathrm{TSH}(\mathrm{Guthrie}$ Test) or T4 collected by heel prick, followed by back up TSH. TSH from a dried filter paper specimen has a false positive to confirmedHypothyroidism ratioof 2 to $3: 1$. However only less than $5 \%$ of newborns can be diagnosed clinically before screening. Measuring thyroxine increases the sensitivity but it increases the cost.Other methods used for the measurement of TSH include Radio Immune Assay (RIA), Enzyme Immuno-Assay (ELISA), chemiluminiscence and Time Resolved Fluorescenseimmuno Assay (TRFIA, DELFIA) which have superior sensitivity and specificity and ease of interpretation of results.

As per the joint guidelines of the American Academy of Pediatrics, American Thyroid Association \& Lawson Wilkins Pediatric Endocrine Society, screening TSH >40 $\mathrm{mU} / \mathrm{L}$ should result in immediate repeat confirmatory sample for $\mathrm{TSH}$. If $\mathrm{TSH}$ is again $>40 \mathrm{mU} / \mathrm{L}$, treatment should commence after documenting a low T4 and an imaging (ultrasonography or radionuclide scan) of the thyroid. If the screen TSH is between $10 \& 40 \mathrm{mU} / \mathrm{L}$, a second screen is obtained in 2 weeks, to allow the hypothalamo-pituitary-thyroid axis to mature. If that second TSH is also between $10 \& 40 \mathrm{mU} / \mathrm{L}$, one may opt to follow up for another 2 weeks or to treat. If treatment is given, it is interrupted after 3 years for 1 month, to reevaluate for permanence of Hypothyroidism.

Common dilemmas in thyroid screening are related to maternal thyroid status, fetal factors like gestational age and maturity of the fetal Hypothalamic-PituitaryThyroid axis, perinatal intranatal factor (use of iodine application during delivery) and mode of delivery. The timing of sample collection for measuring TSH is critical since there is a physiological surge of TSH soon after birth declining to near normal levels approaching 48 hours of age. The reference range is significantly different depending on whether the TSH was measured on a sample taken from the umbilical cord, or soon after birth or at or 48 hours of age.Cord blood TSH are 
Editorial

comparable with filter paper samples [7]. In our country where it is very difficult to call back babies once discharged, cord blood remains a very practical alternative.However it is important to note that various perinatal factors such as gestational age,weight, sex, mode of delivery, Eclampsia, APH, Birth Asphyxia ,PROM, HIV status\& maternal agemay influence cord blood TSH and T4 levels [8].

In India the current challenges to neonatal thyroid screening are lack of a national policy, high home delivery rate, early discharge from hospitals, cultural taboos related to newborns, lack of reliable laboratories on a large scale, and non-availability of baseline data.Another hurdle at national level is the nonavailability of a suitable TSH kit for neonatal screening. Possibility of using hTSH-IRMA kit (supplied by BRIT) for neonatal screening after necessary modifications should be considered [9]. Mass education, media propagation and training centersare required for enhancing the efficacy of screening programs.

Pikala Tarakeswara Rao et al in his study in this issue revealed that FT4 and TSH value varies in neonate with gestational age. We should interpretate these readings with gestational age [10].

\section{Reference}

1. Desai MP, Upadhye P, Colaco MP, Mehre M, Naik SP. Neonatal screening for congenital hypothyroidism using the filter paper thyroxine technique.Indian $\mathrm{J}$ Med Res.1994; 100: 36-42.

2. Desai MP. Congenital hypothyroidism: Screening dilemma. Indian J EndocrMetab 2012;16, Suppl S2:153-5. doi: 10.4103/2230-8210.104027.

3. Kishore KR, Ranieri E, Fletcher J (2014) Newborn Screening for Congenital Hypothyroidism in India- Is overdue. J Neonatal Biol 3:129. doi: 10.4172/21670897.1000129.

4. Kumar K R. Newborn Screening in India: What are the Challenges and Pitfalls? PediatricOncall 01/2014; 11(4).doi: 10.7199/ped.oncall.2014.69.

5. Vinod Bhatara, Rajan Sankar, JurgenUnutzer, John Peabody. A Review of the Case for Neonatal Thyrotropin Screening in Developing Countries: The Example of India. Thyroid. July 2002, 12(7): 591-598. doi:10.1089/105072502320288447.

6. Neha Sareen, Ritu Pradhan. Need for neonatal screening program in India: A national priority. Indian J EndocrinolMetab. 2015 Mar-Apr; 19(2): 204-220.doi: 10.4103/2230-8210.149315.

7. Fuse Y, Wakae E, Nemoto Y, Uga N, Tanaka M, Maeda $\mathrm{M}$, et al. Influence of perinatal factors and sampling methods on TSH and thyroid hormone levels in cord blood. EndocrinolJpn 1991; 38: 297-302.

8. Gurudatt Joshi, RafiqMenon. Profile of umbilical cord blood TSH, T4 and influence of perinatal factors on thyroid functions in Newborns; J Clin Biomed Sci 2014; 4(2):282-85.

9. Sangeeta.N, L. Kamala, ParasKarki .Assessment of umbilical cord TSH in term Neonates in Manipur; IOSR Journal of Dental and Medical Sciences (IOSR-JDMS): 2279-0861. Volume 9, Issue 1 (Jul.- Aug. 2013), PP 1417.

10. Pikala Tarakeswara Rao, Sai Sunil Kishore, Y V Siva Sankara Murty, Pundarikaksha Varanasi, Madhusudhan K, Prudhvi Krishna K. Determinants of thyroid function in neonates at birth. Pediatr Rev: Int J Pediatr Res 2015;2(3):55-61. doi: 10.17511/ijpr.2015.3.006.

\section{How to cite this article?}

Rabindran, Gedam DS. Thyroid screening in neonates: Indian perspective. Pediatr Rev: Int J Pediatr Res 2015;2(3):8-9. doi: 10.17511/ijpr.2015.i03.01 